Evidence and Counter-Evidence, Festschrift Frederik Kortlandt, Volume 2 SSGL 33, Amsterdam - New York: Rodopi, 2008, 415-428

\title{
LANGUAGE, BRAINS AND THE SYNTACTIC REVOLUTION
}

\author{
JEROEN WIEDENHOF
}

\begin{abstract}
'If every single living thing is different from every other living thing, then diversity becomes life's one irreducible fact. Only variations are real. And to see them, you simply have to open your eyes.'
\end{abstract}

Condon (2004)

\section{Form and meaning}

Modern linguistics owes its existence to a consistent distinction between utterances and the symbols underlying utterances, thereby assigning an indirect but crucial role to the physical aspects of human language as evidence for its cognitive architecture. This physical evidence comes in two kinds.

Firstly, an utterance such as that of the English expression rod can be represented by its speech sounds. In other words, saying [ $1 \mathrm{~s}$ d] will excite the recording membrane of an audio device. Secondly, certain poleshaped objects will be deemed appropriate referents of the expression rod by speakers of English. The physical quality of the second kind of evidence, however, requires some discussion in comparable cases. For the expression nod, the status of the uttered sounds [no'd] is no different than that of $[\mathrm{x} \cdot \mathrm{d}]$ in the case of $r o d$, but the referent, i.e. an abrupt movement of the head, may appear less physical than a tangible pole-shaped object. This sense of metaphysical abstraction will be stronger for expressions such as English God.

Language is the symbolic system connecting speech sounds and their referents by means of form and meaning. Linguistic forms are made up of phonemes, the naïve and language-specific cognitive generalizations abstracted from the barrage of phonetic details confronting the speaker's ears. English speakers will analyse $[\mathfrak{d} d]$ as a sequence consisting of the phonemes $/ \mathrm{r} /$, $/ \mathrm{o} /$ and $/ \mathrm{d} /: / \mathrm{rod} /$. On the semantic side, the language user is likewise confronted with a multitude of entities vying for his attention. A native command of English implies the capacity to distinguish an entity which can serve as an appropriate referent of the meaning 'rod' from entities which cannot. Meanings can accordingly be defined as mental 
categories abstracted from the details of referents in the world outside language.

\section{The realization of meaning}

The above description assumes processes of symbolic abstraction leading from speech sounds to linguistic forms and from referents to the meanings of a language. One of the extraordinary features of Carl Ebeling's philosophy of language is his reversal of the sense of direction implied in both types of abstraction: "Each horse is a manifestation of the meaning 'horse', and each pronunciation of the word horse is a manifestation of this word" (1978: 22). In other words, worldly referents are the realized instances of linguistic meanings, just as physical utterances can be seen as the realizations of linguistic forms.

In view of the strong parallelism between form and meaning maintained in Ebeling's work, a semantic counterpart to phonetic speech production would seem to be a necessary consequence of his theory. The full potential of this type of productivity was realized by Frederik Kortlandt (1985), who delineates a gloomy scenario for human hosts as they adapt to the linguistic parasite invading their brains. In this "parasitological view" of language, the reproductive effect of semantic images is deemed so powerful as to reverse the conventional understanding of referent and meaning in terms of original versus derived image. The referent is instead created from linguistic meaning as a manifestation par excellence. In Kortlandt's analysis, the reproductive power of semantic images entails the non-constructibility of a linguistic meaning (p.480). This observation is fundamental, if only because one can never tell if a given meaning, say 'rod', is appropriately applied to a given referent unless it is claimed to be so. In this respect, the statements of a linguistic informant are both unchallengeable and susceptible to shifting values.

The import of the parasitological paradox is not restricted to the realms of linguistics and philosophy. Broad obstructive effects of language on progress in science have been intimated by Gabriel Stolzenberg:

"despite a general awareness that language does seem to have the power to make us 'see things,' it is not taken seriously that language may be a determining influence-and possibly a source of major error-for the contemporary scientist's own 'objective reality': the one into which he enters as a student and then shares with a community of fellow practitioners. However, if there is any lesson to be learned from the case of contemporary mathematics it is that language may be acting upon us in precisely such a way; and that, therefore, it is incumbent upon us as scientists to begin to take this possibility very seriously indeed" (1978: 269). 
Outside academe, the import of the parasitological analysis is more literally devastating. David Brooke's (1997) analysis of international reactions to the outbreak of the Bosnian war in 1992 offers a striking example of conceptual self-manifestation. Brooke argues that "one widespread and utterly fundamental historical pre-conception was that the Balkans were seeing the sudden explosion of ancient ethnic hatreds that had lurked just below the surface of Tito's communist state", so that "war was seen as somehow inevitable, and if war was inevitable, Western attempts to stop it would be futile". Hence the international response, or lack of same, to the first outbreaks of violence was orchestrated by those who "shared the belief". This belief, however, is described as "a complete myth [...] deliberately used to justify the stand of Britain and other governments". The atrocities of the Bosnian conflict may thus be seen as the net effect of deceptive imagery. The self-fulfilling prophecy of the ethnic animosity argument provides a gruesome example of the way in which concepts can materialize their own referent.

If the unleashed power of conceptualization leaves such traces in the history of humankind, the impact of semantics on the hominid mind must have been immense. I will argue below that the syntactic revolution was a direct development from early semantics.

\section{Sound symbolism}

The power of semantic images may in turn be likened to the forceful insistence of the phonological system. Our native command of a language's phonemes influences the way we learn other languages, affecting pronunciation as well as comprehension in second language acquisition. The phonemic system even encroaches upon automatic reflexes. English ouch! and Dutch $a u$ ! both voice spontaneous cries of pain, but nevertheless represent different phonologies. Apart from deafness, only extreme emotions can break the spell of sound symbolism. Lustful sighs and shrieks of total anguish reveal little if anything about our phonological systems.

\section{The evolution of communication}

Whether in chemical, electric, tactile, visual, kinetic or linguistic means of communication, we find, as Philip Lieberman observes, "neural systems matched to peripheral anatomy" (1984: 136), ensuring that the perceptive mechanisms of each species are adapted to its expressive means. Lieberman's plea for a consistent evolutionary treatment of language harks back to Charles Darwin's notion of transitional change: 
"The same organ having performed simultaneously very different functions, and then having been specialised for one function; and two very distinct organs having performed at the same time the same function, the one having been perfected whilst aided by the other, must often have largely facilitated transitions." (Darwin 1996: 232)

This notion of transition allows for an abrupt change of function of an existing structure, arising in one or more individuals. If such a change yields a selectional advantage, it will trigger gradual change in the species. Darwin's example of swimbladders in fishes (pp. 220-221) has not lost its appeal. As these organs of flotation began to be used for respiration, they were transformed through anatomical adaptation, eventually leading to the development of lungs in terrestrial mammals.

Lieberman's surveys $(1984,1991)$ provide a wealth of archeological, neurological and phonetic information on the mechanisms of speech production and auditory reception, making a convincing case for the development of the early hominid speech apparatus through gradual anatomical adaptations. This development is described as an adaptation of the speechproducing organs to the processing limitations of the auditory system. As Lieberman (1984: 147) argues, "[a]t rates that exceed 15 sounds per second, the individual sounds merge into a buzz", i.e., into a single tone of $15 \mathrm{~Hz}$. Vocalizations were limited to nasal sounds varying in pitch, duration and loudness. In modern man, the lowered larynx diverts air streams through the mouth, giving rise to a wide variety of vowel sounds and consonantal distinctions and simultaneously increasing the speed of communication: " $t \mathrm{t}$ ]he rate at which we identify the individual sounds of speech ranges from 20 sounds per second for normal rates of speech to about 30 sounds per second" (ibid.). In other words, the oral tract provided hominids with both qualitative and quantitative specialization for speech.

Data from studies of vocal communication in modern non-human primates, when cautiously applied, have proved useful in the reconstruction of the earliest history of language in humankind. Vervet monkeys (Cercopithecus aethiops), whose common ancestor with humans and apes dates back some 25 million years, use clearly distinct calls to warn conspecifics against leopards, eagles or snakes. These alarm calls have been the subject of wide ethological interest ever since Thomas T. Struhsaker (1967) published his observations on vocalizations of vervets in the Amboseli Reserve of Kenya. An overview of the field is given by Dorothy L. Cheney and Robert M. Seyfarth (1990: 102-110), with additional data on the same population. 
Apart from alarm calls, vervets make use of a less conspicuous type of vocalizations known as "grunts". These sounds used to be regarded as general purpose contact calls:

"Even to an experienced human listener, there are no immediately obvious audible differences among grunts, either from one context to another or across individuals. When grunts are displayed on sound spectograms, there are also no consistent differences in acoustic structure from one context to the next [...] Although grunts are occasionally answered by other group members, in most cases grunts evoke no salient behavioral responses. Changes in the direction of gaze, which are difficult to measure in the wild, seem the only obvious response when one individual grunts to another." (Cheney \& Seyfarth 1990: 114-115)

Later experiments have demonstrated that this acoustic uniformity is in fact a human bias: vervet monkeys are perfectly capable of making consistent distinctions between the acoustic properties of different grunts. Cheney \& Seyfarth describe grunts on the occasion of meeting with subordinates, grunts used with a dominant individual, grunts made to an animal moving into an open area, and grunts intended for members of another group. The failure to discover "consistent differences" in the spectograms parallels the situation in human phonology, where phonetic data cannot be interpreted without information about the phonological distinctions made by the vocalizing subject.

The experimental identification of different grunts allows for a better understanding of social relations between vervet monkeys, e.g. in migrant behavior. Vervet males migrating to new groups initially establish foraging and feeding relationships, but return to their old groups to rest. It had previously been assumed that sleeping with the new group signalled the successful completion of the transfer. However, it is now clear that newly arrived males continue to be regarded, and continue to regard themselves, as outsiders, as evidenced by mutually persisting grunts typically reserved for members of another group. In-group grunts used in dealing with dominant and subordinate individuals develop after approximately two weeks, establishing full social acceptance (Cheney \& Seyfarth 1990: 118119).

\section{Primate and hominid vocalizations}

Since alarm calls help vervet monkeys to evade predators, their evolutionary survival value is hardly open to question. The evolutionary significance of grunts must be sought in their social value. The complex 
structure of primate societies is a familiar theme in ethology and anthropology, and the special role of social intelligence in the development of human language is well explored (Dunbar 1996, Mithen 1998). Both vervet grunts and human language help to establish cohesion in social groups, where individuals need to keep track not only of their relationships to others, but also monitor the relationships between other individuals. The average size of the group of conspecifics about whom primates possess practical social knowledge ranges from approximately 25 for vervet monkeys to 50 for chimpanzees and 150 for humans. The increase in the number of binary relations within the social group is exponential: an individual living in a group of 25 will deal with a maximum of 300 internal relationships, a group size of 150 yields the possibility of 11,175 such relationships, the general case amounting to $1 / 2\left(n^{2}-n\right)$ relationships for $n$ individuals. Increased brain size in the hominid lineage may have supplied much of the processing power required for the social complications of large communities, but as I will argue below, the earliest differences between language and non-human primate vocalizations were qualitative rather than quantitative in nature.

Among quantitative issues, the limited repertoires of non-human primate vocalizations can be puzzling:

"Vervets may be able to divide a graded series of sounds into discrete categories, but their repertoire of calls, compared with human language, is still not very large. In terms of evolutionary function, we can easily explain why the vervets have so many grunts, but we cannot explain why they have so few." (Cheney \& Seyfarth 1990: 120)

This discrepancy may largely be resolved if, following the analogy introduced in section 4, a call or a grunt is considered as an analogue to the human phoneme. A vervet's grunted phoneme combines with a simple notion, e.g. 'stranger here', to form the vervet equivalent of a morpheme. The use of this single morpheme is, in human terms, equivalent to the uttering of a simple sentence. In other words, each distinct vocalization constitutes not just the smallest possible message, but also the largest possible message. Judged in this light, the qualitative difference between primate vocalizations and human language seems to lie in the combinatory powers of syntax.

\section{Complexity in proto-syntax}

It has been argued that for two juxtaposed signs, the availability of more than one meaning of the expression as a whole is the hallmark of syntax; e.g. Mandarin shān 'mountain', shǔ̌ 'river', shānshǔ̀ (a) 'mountains 
and rivers', (b) 'water from the mountains' (Wiedenhof 1996: 141). But the availability of more than one meaning defines syntax even in the absence of juxtaposition, e.g. shān (a) 'mountain', (b) 'there is a mountain', referring to the mountain as an entity and as a situation, respectively. Syntactic distinctions of this type have engendered some discussion about the direction of derivation between these two meanings.

Ethologists, neurologists and linguists tend to agree that the emergence of symbolic signals is closely linked to the origin of language; and that the relevant brain size of apes, hominids and humans correlates with an increase in symbolic complexity. Opinions differ, however, as to what constitutes (1) syntax at the earliest symbolic stage and (2) syntactic complexity.

(1) Evolutionary accounts of the syntax of symbols do not always distinguish between syntax and word order, or the juxtaposition of symbols. In Sverker Johansson's (2006: 163) reconstruction, for instance, a "one-word stage" characterized by "basic semantics with no syntax" precedes the "two-word stage" characterized as "Structured":

"Structured in the sense that an utterance is not just a random juxtaposition of words, but in some way indicates the relations between words. The structure indicators may be linear order, or morphological markers, or whatever. [...] Structured must be the first syntax feature to emerge."(pp.161-163)

If "basic semantics" precludes syntax, this may leave semantic reconstruction as an afterthought, or as a matter to be dealt with separately from syntactic reconstruction. But if meaning is to be accounted for in our reconstruction of incipient syntax, as I think it should, then the possibility of syntax at the "one-word stage" will have to be considered as a primitive option.

(2) Opinions also differ as to what constitutes symbolic complexity in its early syntactic sense.

According to Terence Deacon, "early hominids were forced to learn a set of associations between signs and objects, repeat them over and over, and eventually unlearn the concrete associations in favor of a more abstract one" (1997: 402). This equivalence of "objects" with "concrete" notions is reaffirmed in Charles N. Li's account of the emergence of symbolic signals:

"the dawn of symbolic communication was initiated behaviorally by a hominid in the genus Homo. In particular, this behavior is the creation of a communicative signal refering to a concrete object" (Li \& Hombert 2002: 191)

"symbolic communication begins with concrete nouns in hominid evolution. [...] The appearance of a communicative signal that symbolizes an abstract entity such as an 
event or action represents a quantum leap toward the crystallization of language" (Li 2002: 89-90).

Applied to the previous example, the event meaning of (b) shān 'there is a mountain' is an abstraction, reflecting a cognitively more complex stage than its concrete noun variant, (a) shān 'mountain'.

It has been contended, however, that the inverse relationship may in fact hold for the early linguistic brain handling information such as the discovery of a mountain in the landscape (Li et al. 1998, Wiedenhof 2003). This information, culled from the sense organs, would result in a mental state representing a situation in which a mountain is present. Physically, this mental image is created by synaptic proteins, and functionally, the representation is a symbolic reproduction of a 'mountain' situation. Syntax and linguistic semantics developed when the brain was able to represent the same situation twice, from two different perspectives, and to combine these two perspectives in one global view.

I concur with Ebeling (2006: 36) that the division of indivisible notions is a cognitive feat which made the emergence of language possible. Modern brains universally distinguish between the notion of an entity per se and the notion of a situation containing that entity. This means that modern languages can conceptualize sensory information about a mountain in two ways: (a) as the notion of a mountain; and (b) as the notion of a situation in which a mountain is present. This mental split allows for coreferentiality, i.e. two notions referring to the same external entity. Coreferentiality is a fundamental syntactic function common to all human languages.

The syntactic revolution bestowed a temporal quality upon the cognitive representation of a situation, and by contrast, the entity itself was represented as being devoid of time. The awareness of the passing of time crucially depends on the capacity for coreferentiality. It arises when the awareness of a situation, in the form of a fresh mental copy, is supplemented with the notion of a contrasting situation. In our example, the notion of a situation in which a mountain is present ('there is a mountain') co-emerges with a new conceptual unit (the 'mountain' as an entity) from an earlier all-inclusive view (the 'mountain' situation). Henceforth the notion of the entity can be contrasted with a situation without that entity. The comparison presupposes the ability to store a mental copy of the situation without a mountain: temporal awareness requires the coexistence of both notions. This effect is dimensional in the mathematical sense. Time yields an extra perspective, just as a three-dimensional observer may view a sheet of paper as consisting of two distinct two-dimensional surfaces, 
all the same realizing that the front and the back belong to the same sheet (cf. Wiedenhof 1995: 36-38).

From the perspective of modern languages, the notion 'there is a mountain' may appear more sophisticated than the notion 'mountain' which often requires less complex expression types: in the case of English, a single noun as opposed to a declarative sentence. It is therefore tempting to view the linguistic symbolization of situations such as events and actions as more abstract in nature than the representation of objects and other entities. At the earliest syntactic stage, however, entities were more likely abstracted from situations than vice versa.

This point may be argued on selective grounds. When an approaching leopard requires urgent action from a primate brain, the threat will typically be due to the situation brought about by the leopard. Biological survival strategies therefore have little need for a cognitive distinction between the notion 'there is a leopard' from the notion of a 'leopard' isolated from its situational background. The undivided representation of the situation is therefore cognitively more basic, and the notion of an entity is a derived syntactic abstraction.

\section{Synkinetics and exploratory behavior}

Syntax at the "one-word stage" thus occupies a halfway point between the messages encoded in single grunts and the meanings expressed by compound sentences. As a syntactic mechanism, the split of basic situational notions into temporal events and non-temporal entities complements the well-advertized combinatory power of syntax. Both mechanisms create new entities subject to selective pressures in the development of language.

The contiguity between cerebral functions, culture and language suggests integrated evolutionary treatment of biological, neurological, cognitive, behavorial, social and linguistic mechanisms. The complex interdependence of organs, organisms and superorganisms renders the use of such terms a matter of convenience, depending on one's area of interest. An anatomical analysis may describe my kidney as an organ in a human body. In histology, this organ may be regarded as a structure built from living cells. And in molecular biology, the same cells may be described as highly complex self-replicating organisms. To return to the ant colony: if an ant is an individual organism just like any other insect, then a colony displaying complex foraging strategies may be called a superorganism (Gerhart \& Kirschner 1997: 148-151, Voormolen 2006: 47).

As suggested by Gerhart \& Kirschner's analysis of ant behavior, "exploration may be the simplest mechanism for responding to complex inputs" 
(p. 151). On a human scale, very similar exploratory behavior is displayed by linguistic meanings colonizing the human brain, as pointed out by Kortlandt (2003: 243). Another human parallel can be found in what I will call synkinetics: the phenomenon of two or more organisms moving together in time. This example is here offered as a tribute to Frederik Kortlandt, who mastered dance before he devoted his life to fundamental research.

The history of human synkinetics has been documented in a lucid monograph by William H. McNeill (1995). "Rhythmic muscular expressions of group excitement" (p. 101) are exemplified in dance, shamanism, ritual postures, religious processions, football hooliganism and political frenzy. Synkinetic survival value is found in religious bonding, military campaigns and industrial health care. Examples of animals relying on synkinetics are geese flying in a flock and dolphin calves copying the movements of their mother; primate parallels are found in chimpanzee "rain dance" displays and dancing games. This evidence suggests that synkinetics is much older than language: "human evolution may have involved two critical transformations, both of which centred on improved communication. First, the dance and the emotional linkages that it established; then, articulate speech and the symbolic linkages which fully developed language allowed" (p.35).

Recent DNA sampling of dancers (Rachel Bachner-Melman et al. 2005) testifies to the age of the dual communicative and emotional qualities identified by McNeill. Two genes representing the human "dance phenotype" are the arginine vasopressin 1a receptor (AVPR1a), affecting social communication; and the serotonin transporter (SLC6A4) which is associated with spirituality. Thanks to a "surprisingly conserved evolutionary history", human dance is shown to be biologically related to "mating displays and affiliative behavior observed across the vertebrates" (p.400).

A military example of synkinetic survival value is the introduction of close-order drills by Captain General Maurice of Orange at the turn of the $17^{\text {th }}$ century. Inspired by his study of the Greek and Roman classics with Justus Lipsius at Leiden, Maurice adapted Macedonian models to new contingencies:

"The practical importance of such pedantry was very great. In principle and to a surprising degree also in practice, it became possible to get soldiers to move in unison while performing each of the actions needed to load, aim, and fire their guns. The resulting volleys came faster, and misfires were fewer when everyone acted and kept time to shouted commands. Practice and more practice, repeated endlessly whenever spare time allowed, made the necessary motions almost automatic and 
less likely to be disrupted by stress of battle. More lead projected at the enemy in less time was the result: a definite and obvious advantage when meeting troops not similarly trained." (McNeill 1995: 128)

McNeill concludes that "[s]uch an army, in effect, had the advantages of a central nervous system" (p. 130). The proverbial esprit de corps can therefore be taken quite literally, for Maurice's infantry acted as a superorganism of human individuals with a common purpose in mind.

As in the case of linguistic meaning, synkinetics organizes exploratory behavior in units beyond the human individual. The structure of such units does not rely on rigidity alone, as suggested by Gerhart and Kirschner's ant colonies: "a certain instability or randomness in the foraging can be useful so that the colony will not be trapped in a local maximum of efficiency" (1997: 149). The "lost ant", in other words, may discover a hitherto undiscovered source of food, allowing the colony to adapt to new contingencies.

In linguistic behavior, such random mechanisms are well attested. One example is the ease with which speakers across age groups and social backgrounds admit to having experienced situations in which the talking somehow took control of itself, making them wonder afterwards: "why on earth did I say that?" This phenomenon is perhaps best observed at moments of social awkwardness. But even in friendly environments, the use of language may lead to unpredictable consequences. This is because linguistic meanings easily lend themselves to ever new applications, inducing fresh memetic mutations.

Like the "lost ant" hitting upon a new source of food, this random aspect in the transmission of linguistic meaning can be a blessing in disguise. Anyone wrestling with tenacious questions naturally resorts to the semantic categories provided by language. And to an observable extent, these categories appear to be self-organizing and quite beyond our active control. In the classical Héuréka! example, the rising water in a bath tub helped Archimedes solve a problem of specific gravity, but it may be just as significant that the solution came to him in a moment of relaxation. Such experiences are shared by many, and may be expressed by claims that solutions suddenly "hit us", making "everything fall into place": in the shower, during a stroll in the yard, or after a good night's sleep.

\section{Conclusion}

The syntactic revolution was a direct development from primitive linguistic semantics. Its earliest tentative date is the beginning of the Pleistocene, 1.8 million years ago, when the appearance of Homo erectus heralded an 
epoch of rapid increase in brain volume for our lineage. The latest acceptable date is the Upper Pleistocene, or 40,000 years ago, when the development of art, burials, religion, and personal decoration demonstrate that language was firmly entrenched in the anatomically modern human brain. Both dates would mean that spectacular developments have taken place within a short period of evolutionary time. It is therefore safe to conclude that the association between language and the brain accommodating language is far from stable.

Leiden University

\section{REFERENCES}

Bachner-Melman, Rachel, Christian Dina, Ada H. Zohar, Naama Constantini, Elad Lerer, Sarah Hoch, Sarah Sella, Lubov Nemanov, Inga Gritsenko, Pesach Lichtenberg, Roni Granot, Richard P. Ebstein

2005 "AVPR1a and SLC6A4 gene polymorphisms are associated with creative dance performance". PLoS Genetics 1(3): e42. Open Access, http://genetics.plosjournals.org/archive/1553-7404/1/3/pdf/10.1371

Brooke, David (producer) journal.pgen.0010042-L.pdf, 30 September. Accessed 3 February 2006.

1997 "Policy and prejudice", Part 1. BBC World Service radio transmission, 30 March, 648 kHz, 17:00-17:30h GMT.

Cheney, Dorothy, and Robert M. Seyfarth

1990 How monkeys see the world: Inside the mind of another species. Chicago: University of Chicago Press.

Condon, Bill (writer \& director)

2004 Kinsey. Los Angeles: $20^{\text {th }}$ Century Fox Film Corporation. The quotation in the motto appears at $12^{\prime}: 29^{\prime \prime}-12^{\prime}: 42^{\prime \prime}$, showing Liam Neeson as Alfred Kinsey commenting on the biological implications of his extensive ento-

Darwin, Charles mological research; cf. Kinsey (1930: 5-77).

1996 The origin of species. New York: Gramercy Books. Reissue of the first edition, On the origin of species by means of natural selection, London: J. Murray, 1859.

Deacon, Terence

1997 The symbolic species: The co-evolution of language and the human brain. Lon-

Dunbar, Robin

1996 Grooming, gossip and the evolution of language. London: Faber \& Faber.

Ebeling, C.L.

1978 Syntax and semantics: A taxonomic approach. Leiden: E.J. Brill.

2006 Semiotaxis: Over theoretische en Nederlandse syntaxis. Amsterdam: Amsterdam University Press. 
Edelman, Gerald M.

1987 Neural darwinism: The theory of neuronal group selection. New York: Basic Books.

Gerhart, John, and Marc Kirschner

1997 Cells, embryos and evolution: Toward a cellular and developmental understanding of phenotypic variation and evolutionary adaptability. Malden: Blackwell Science.

Johansson, Sverker

2006 "Working backwards from modern language to proto-grammar". In: Angelo Cangelosi, Andrew D.M. Smith and Kenny Smith (eds.) The evolution of language: Proceedings of the $6^{\text {th }}$ International Conference, 160 175. Singapore: World Scientific.

Kinsey, Alfred C.

1930 The gall wasp genus Cynips: A study in the origin of species. Indiana University studies XVI. Bloomington: Indiana University.

Kortlandt, Frederik

1985 "A parasitological view of non-constructible sets". In: Ursula Pieper and Gerhard Stickel (eds.), Studia linguistica diachronica et synchronica: Werner Winter, sexagenario anno MCMLXXXIII gratis animis ab eius collegis, amicis discipulisque oblata, 477-483. Berlin: Mouton.

2003 "The origin and nature of the linguistic parasite". In: Brigitte Bauer and Georges-Jean Pinault (eds.), Language in time and space: A festschrift for Werner Winter on the occasion of his 80th birthday, 241-244. Berlin: Mouton de Gruyter.

Li, Charles N. (speaker), George van Driem, Frederik Kortlandt, Jeroen Wiedenhof (discussants)

1998 Discussion following Li's lecture “'Cyclic Morpho-Syntactic Change' in Chinese", Leiden University, 20 April.

Li, Charles N. 2002

"Missing links, issues and hypotheses in the evolutionary origin of language". In: T. Givón and Bertram F. Malle (eds.), The evolution of language out of pre-language, 83-106. Amsterdam: John Benjamins.

$\mathrm{Li}$, Charles N., and Jean-Marie Hombert

2002 "On the evolutionary origin of language". In: Maxim I. Stamenov and Vittorio Gallese (eds.), Mirror neurons and the evolution of brain and language, 175-205. Amsterdam: John Benjamins.

Lieberman, Philip

1984 The biology and evolution of language. Cambridge, Massachusetts: Harvard University Press.

1991 Uniquely human: The evolution of speech, thought and selfless behavior. Cambridge, Massachusetts: Harvard University Press.

McNeill, William H.

1995 Keeping together in time: Dance and drill in human history. Cambridge: Harvard University Press.

Mithen, Stephen

1998 The prehistory of the mind: A search for the origins of art, religion and science. London: Phoenix. Original edition London: Thames \& Hudson, 1996. 
Stolzenberg, Gabriel

1978 "Can an inquiry into the foundations of mathematics tell us anything interesting about mind?". In: George A. Miller and Elizabeth Lenneberg (eds.), Psychology and biology of language and thought: Essays in honor of Eric Lenneberg, 221-269. New York: Academic Press.

Struhsaker, Thomas T.

1967 "Auditory communication among vervet monkeys (Cercopithecus aethiops)". In: Stuart A. Altmann (ed.), Social communication among primates, 281-324. Chicago: University of Chicago Press.

Voormolen, Sander

2006 "De mier is in balans, de mens niet: Edward O. Wilson over [het] wereldsucces van de mieren" [Ants are in balance, humans are not: Edward O. Wilson on the ant's worldwide success]. NRC Handelsblad: Wetenschap $\mathcal{E}$ onderwijs, 20 May, p. 47.

Wiedenhof, Jeroen

1995 Meaning and syntax in spoken Mandarin. Leiden: CNWS Research School. 1996 "Nexus and the birth of syntax". Acta linguistica Hafniensia 28, 139-150.

2003 "On the origins of linguistic meaning". Lecture delivered at the NWO Cognition Workshop, The Evolution of Meaning in a Game-Theoretical Setting: Cognitive constraints and Experimental Architecture. Amsterdam: Koninklijke Nederlandse Akademie van Wetenschappen, 4 September. 